\title{
School Intrusion Notification and Alarm System Using Face Recognition
}

\author{
Romeo E. Balcita ${ }^{1}$, Rommel E. Balcita ${ }^{2}$ and Thelma Domingo Palaoag ${ }^{3+}$ \\ ${ }^{1,2}$ Northern Philippines College for Maritime, Science and Technology San Fernando City, La Union, \\ Philippines \\ ${ }^{3}$ University of the Cordilleras, College Research Coordinator Baguio City, Philippines
}

\begin{abstract}
In a school, security is very crucial to prevent intrusion that may lead to crime. With a few guard stations in the school, unauthorized person could enter the school premises and could make a crime. With the added CCTV's it can be used to review the recorded video to what happened when a crime was reported. Authorized personnel, students, and offices are not $100 \%$ secured but to increase security, improving the security systems in school will help and prevent such crimes. Students and employees of the school must be identified as well as guest as they enter the school to know if they are authorized to enter or not. This study aims to develop a security system in schools to identify each person's face that enters the school and notify the guard on duty if the person is an intruder or not, by using face recognition technique, students, employees and guests must be registered into the system saving their records and face information. The real time video from the CCTV will be scanned by the system and get face information comparing it to the database. Unidentified faces will be identified as intruders activating an alarm and notifying the guard on duty to check the posted image on monitor screen at the guard station. In the facial recognition algorithm, Principal Component Analysis is used with Eigenface to store and compare faces in the database. Level of effectiveness was identified using Technology Acceptance Model (TAM) using these variables, Information Quality, System Quality and Information Use. The system's usability test will be done using the Quick and Dirty test questionnaires with 10 security guards in the school and 12 ROTC Officers. Enhancement in security is needed in the school, with the study proven to be effective, the schools security surely increases.
\end{abstract}

Keywords: Facial Recognition, Face Detection, Computer Vision, Security Systems.

\section{Introduction}

Intrusion detection is the act of detecting a trespasser in a guarded zone. Human intrusion detection system is a system used to detect human trespasser entering a prohibited area [1]. Conventional human intrusion detection system uses burglar alarm system (active or passive sensors), whereby modern human intrusion detection system applies computer vision techniques, both to trace out whether there is an existence of a trespasser/human being or not in a prohibited area [2]. The main merit of modern human intrusion detection system as compared to conventional human intrusion detection system is that the image processing-based human intrusion detection system can help capture pictures. Since pictures are captured, there are more chances of the intruders being recognized and caught. The authority can wisely place security cameras in every vulnerable place of the guarded area, indoor and outdoor, that would be accessible to a human intruder. This allows the authority to stay safe inside the premise while still being able to see what is happening in the outdoor area of the premise. It also gives them more time to call for help or backup if they notice any security threat [3].

According to tort law, property law, and criminal law, a human intruder is a person who commits the act of trespassing/intruding on a prohibited area, that is, without the permission of the authority. A human

\footnotetext{
+ Corresponding author. Tel.: + Tel no.: 0639493666795.

E-mail address: tpalaoag@ gmail.com.
} 
intruder trespasses to a critical infrastructure's perimeter and the border security is defined as "an intentional interference with the infringement onto national security that proximately will cause injury, vandalism, terrorism, theft, etc." [4]. In United Kingdom jurisdictions, trespassing has been codified to clearly define the scope of the remedy, and in most jurisdictions, trespassing remains a purely common law remedy, the scope of which varies by jurisdiction [5].

Surveillance is very useful to security authority to recognize and monitor threats and prevent criminal activity [6]. Human intruder surveillance system can be used to help security authority guard a critical infrastructure's perimeter and the border security. It is designed to detect an intrusion, activate a warning device upon detection of an intrusion, determine crime, protect life and property, bring an appropriate response to an emergency, and enhance the apprehension of criminals. Human intruder surveillance system can be divided into three main categories, which are the conventional burglar alarm system, the radar-based human [7].

Closed Circuit Television (CCTV) is a surveillance device commonly used in schools internationally to safeguard students, personnel and properties. Schools had become the safest place for young people than in their own communities and in homes [8]. In Korea, an outsider access management system was designed and implemented to deal and help prevent with the intruder kidnapping of students in elementary schools [9].

Security nowadays is a crucial part of our life. Having security Guards are common type of having security but still it is not $100 \%$ secured. Using CCTV cameras are becoming a security of choice by many but that is not enough. If only it can notify the authorities immediately before an intrusion occurs then it can have better security. It is better if it can identify and apprehend immediately the person before something wrong happens. It can be also used to notify security personnel to check on the persons' concern before making preventive actions. But, this can be done by creating a system with facial recognition that uses CCTV devices.

In a school, security is very crucial. Crime happens daily and that anyone are not fully secured in every place they go. People will never be $100 \%$ secured but to increase the security, improving and innovating security systems in our area is the solution. Students and employees must be identified as well as guest that enters the school to know if there is an intrusion in the school from unknown or unlocked entrances.

\subsection{Conceptual Framework}

Intrusion detection has been one of the priorities in companies. Common practice to detect human intrusion is the manual way of guarding the company through a security guard. With the advancement of technology, companies that have CCTV cameras along with security guards become a redundancy. But we can't eliminate security guard; instead we can increase their security capability and make their task easier and faster detection of intrusion.

The system structure of the School Intrusion Notification and Alarm System (SINAS) uses the CCTV's installed at the entrances of the school with guard stations equipped with the computer station. The setup will be the new tool in detecting intrusion with in the school premises. SINAS uses Principal Component Analysis (PCA) in face detection and analysis. PCA is used to reduce the number of variables in face recognition. Every image in the training set is represented in linear combination of weighted eigenvectors called eigenfaces. These eigenvectors are obtained from covariance matrix of a training image set. The system interface contains a face training module and the detection with alarm system module respectively. In the training module, faces of authorized personnel and students will be processed and stored in a database, see Figure 1. The detection and alarm module contains a video screen linked on the CCTV's IP address, detecting multiple faces and activates an alarm when a face is not recognized. An audible alert sound is heard and the guard responds checking the screen to identify the intruder then approaches the person for necessary and proper actions. 


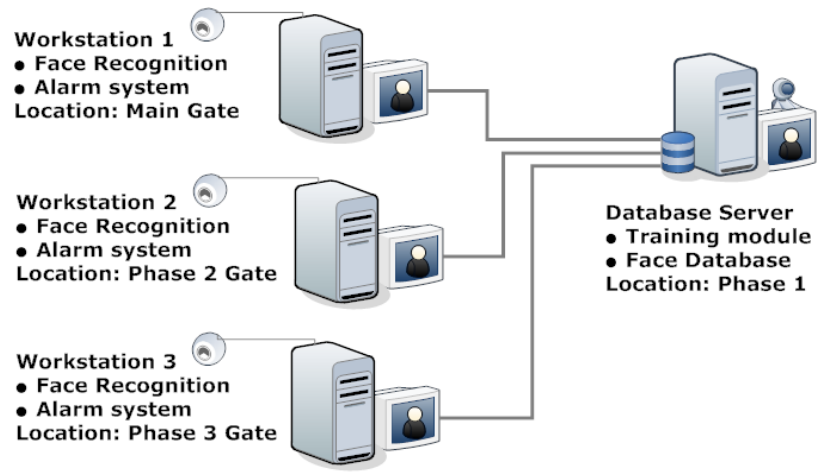

Fig. 1: System structure.

This study uses Server-based systems that enable more complex analysis. All images captured by cameras are sent to a central server that analyzes them with stronger processing power, more memory, higher-speed data base access and more sophisticated software.

\section{Methodology}

The study is a combination of quantitative, descriptive and experimental research. Since, there are two basic techniques in descriptive research: cross-sectional and longitudinal. For the purposes of this study, a cross-sectional study was chosen as the most appropriate technique due to time constraints and moreover this study did not intend to observe trends over time.

To determine the level of effectiveness of facial recognition system to security system, 10 school security guards and 12 ROTC Students were the participants in this study. Each was given a chance to evaluate the system using the System Usability Scale (SUS) questionnaire that is used in evaluating system usability.

Using SUS, the usability test is driven from the School Intrusion Notification and Alarm System Using Face Recognition. The SUS was invented by John Brooke who, in 1986, created this 'quick and dirty' usability scale to evaluate practically any kind of system [10]. The SUS is a Likert Scale which includes 10 questions that can be used by users to evaluate a system and SUS score as a reference on system usability, seen in Figure 2.

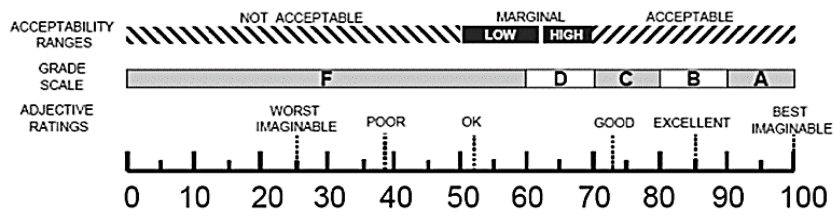

Fig. 2: SUS score guide.

Determining the level of effectiveness of a system needs to consider several factors. System service quality does influence user satisfaction [11]. Given the importance of including service quality as an appropriate surrogate for system effectiveness, a model adopted from the study of Pitt et al is used in this study as shown in figure 3 .

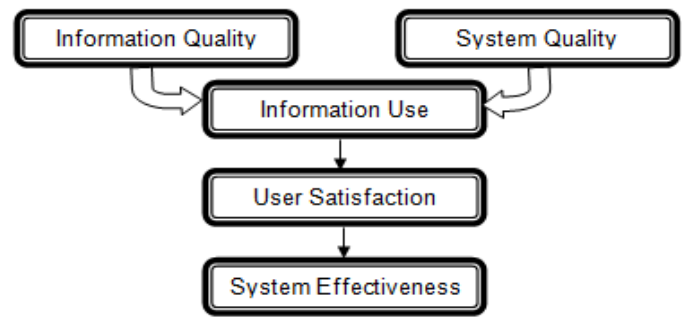

Fig. 3: Factors affecting system effectiveness.

For the part of Information Use, the Technology Acceptance Model (TAM)[12] is used, in Figure 4. This model is rooted to the theory of reasoned action, a model concerned with determinants of consciously intended behaviors. This theory proposes that beliefs influence attitudes, which in turn lead to intentions, and 
then generate behaviors. This model assumes that beliefs about usefulness and ease of use are always the primary determinants of IT/IS adaptation in organizations.

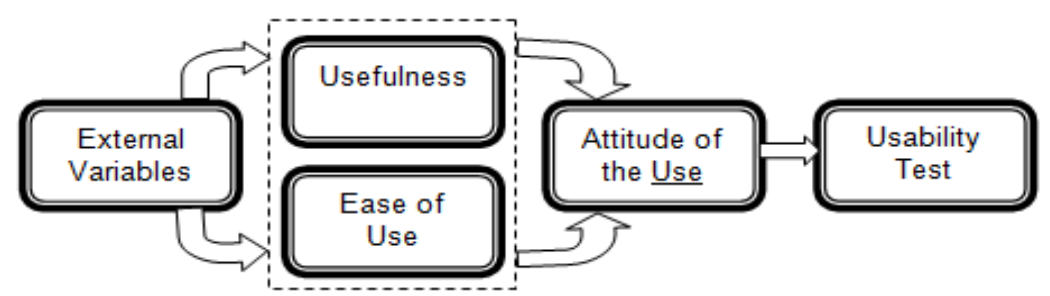

Fig. 4: Technology acceptance model。

\section{Discussion of Findings}

With the advancement of technology, security can be improved. The study aims to improve security in schools by making a school intrusion notification and alarm system using face recognition.

Architectural Framework. This study uses Agile Web Engineering (AWE), as shown in figure 5 below. This model is good for a project that requires limited time.

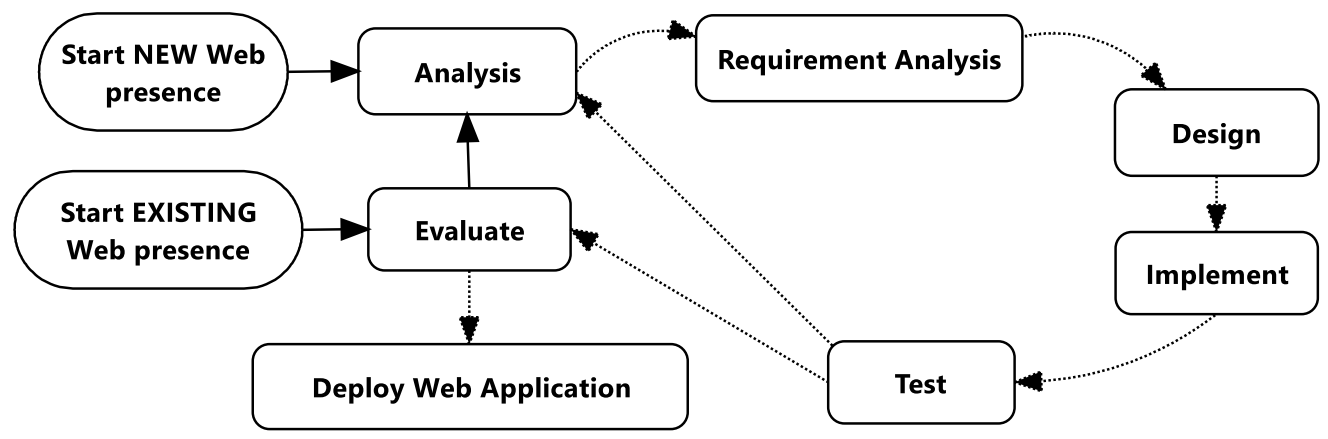

Fig. 5: AWE Development Cycle.

With the use of Visual Basic and SQL, the algorithm PCA and Eigenface conversion in facial detection and recognition, the process becomes easier. The training module for face detection and recognition system is assigned to a server, while the workstations connect to the server and uses the shared face detection system.

Effectiveness level. A pilot question was distributed to the users. The final questionnaire to which the respondents indicated their agreement on a five-point Likert scale (from strongly disagree to strongly agree). The school consisted of ten security guards; five are assigned on duty in the morning till afternoon and another five from afternoon till morning. Officers of the ROTC are also among the sample participants for they are also involved in the security of the school. The questionnaire was adapted to the study conducted by Majid Ramezan in 2009 to get the effectiveness of their system. The table below shows the content of the questionnaire used.

Table 1: Dimension and measures of system effectiveness

\begin{tabular}{|l|l|l|}
\hline \multicolumn{1}{|c|}{ Information Quality } & \multicolumn{1}{|c|}{ System Quality } & \multicolumn{1}{c|}{ System Use } \\
\hline Accuracy & User Limitation & Job Performance Improvement \\
\hline Preciseness & Ease of System Use & Goal Achievement \\
\hline Completeness & Presenting Integrated Reports & Flexibility \\
\hline Timeliness & Response Time & Ease of doing task in using the system \\
\hline Compatibility & $\begin{array}{l}\text { Changeability in the system } \\
\text { Condition }\end{array}$ & User Friendliness \\
\hline Understandability & $\begin{array}{l}\text { Prevention form Program } \\
\text { Interruption }\end{array}$ & Productivity \\
\hline Volume Appropriateness & & Data Transaction Speed \\
\hline
\end{tabular}

For determining the effectiveness of the system, three independent variables are of relevance: Information Quality, System Quality and Information Use. This formulates to the following hypothesis: 
1. Users are satisfied by the system quality.

2. Users are satisfied by the information quality of system

3. Users are satisfied by using the system

According to the results of data analysis, all hypotheses are confirmed. The statistical significance was established at 0.05 . Therefore, the system is identified as effective.

Usability of the System. The computed score will be compared to the given predictor measure from SUS score guide. The 22 participants had been given a 10-questionnaire from SUS to evaluate the usability of the system, wherein figure 5 contains the chart of the data. For each of the odd numbered questions, subtract 1 from the score. For each of the even numbered questions, subtract their value from 5 . Take these new values which you have found, and add up the total score. Then multiply this by 2.5 . The computed SUS mean score results of the 12 ROTC student participants achieved an average score of 83.125 , while the 10 security guards scored 85 and the overall average computed usability score of the system is 84.0625 . The usability score ranged under "acceptable" and has achieved a grade scale of "B" with an adjective equivalent rating "Excellent".

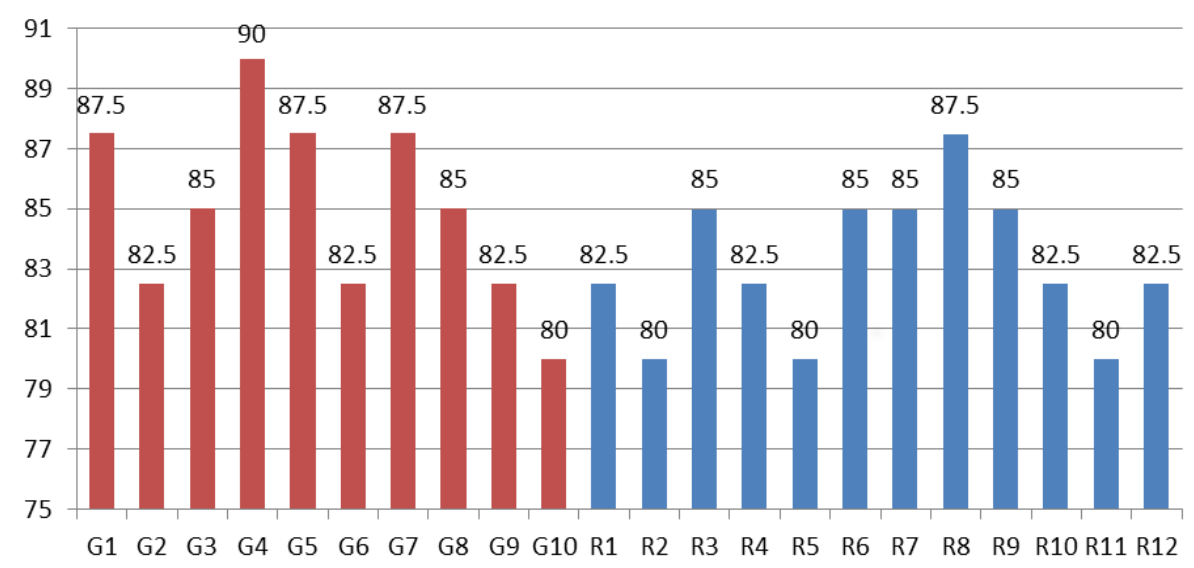

Figure 5. Participants SUS score.

The SUS 10-question evaluation guide in table 2, summarizes the results of the 22 participants. Mean score that achieved 3.59 showing 2 high scores representing a positive remark from the respondents. Also, the result falls on fairly acceptable rates of the SUS scale shown in Figure 2. Based on the Likert scale, the average mean result of the SUS 10-question, all showing under fair usability level.

Table 2: Questionnaire mean scores.

\begin{tabular}{|l|c|}
\hline \multicolumn{1}{|c|}{ SUS 10 template questions } & Mean Score \\
\hline 1. I think that I would like to use this system frequently. & 3.59 \\
\hline 2. I found the system unnecessarily complex. & 3.14 \\
\hline 3. I thought the system was easy to use. & 3.59 \\
\hline 4. I think that I would need the support of a technical person to be able to use this system. & 3.32 \\
\hline 5. I found the various functions in this system were well integrated. & 3.27 \\
\hline 6. I thought there was too much inconsistency in this system. & 2.95 \\
\hline 7. I would imagine that most people would learn to use this system very quickly. & 3.45 \\
\hline 8. I found the system very cumbersome to use. & 3.50 \\
\hline 9. I felt very confident using the system. & 3.50 \\
\hline 10. I needed to learn a lot of things before I could get going with this system. & 3.27 \\
\hline
\end{tabular}

For determining the effectiveness of the system, three independent variables are of relevance: Information Quality, System Quality and Information Use.

Using SPSS, data gathered were entered in the application and produces the following result. According to the results of data analysis, all hypotheses are confirmed. The statistical significance was established at 0.05 . Therefore, the system is identified as effective. 
Table 3: Statistical results

\begin{tabular}{|r|l|l|l|}
\hline Category & $\mathrm{N}$ & Observed Prop & Test Prop \\
\hline Information Quality & & & 0.5 \\
\hline ROTC Officers & 12 & $\mathrm{p}=0.82$ & \\
\hline Guards & 10 & $\mathrm{q}=0.12$ & \\
\hline Total & 22 & 1.00 & \\
\hline System Quality & & & 0.5 \\
\hline ROTC Officers & 12 & $\mathrm{p}=0.92$ & \\
\hline Guards & 10 & $\mathrm{q}=0.08$ & \\
\hline Total & 22 & 1.00 & 0.5 \\
\hline System Use & & & \\
\hline ROTC Officers & 12 & $\mathrm{p}=0.90$ & \\
\hline Guards & 10 & $\mathrm{q}=0.10$ & \\
\hline Total & 22 & 1.00 & \\
\hline
\end{tabular}

\section{Conclusion and Recommendation}

School Intrusion Detection needs continuous enhancement. Using ICT's improves security with integration of dedicated Software. This study aims to enhance school security by detecting human intrusion through face recognition. Security improves but due to poor camera resolutions the desired result was not fully attained. Different types of cameras are now available to the market. We have smart cameras that can further improve the performance of the system. Since the server is located in the main gate, when visitors enter the other gate, they need to go first to the main gate for registration of entry. So, additional workstation is needed in every gate for efficiency purposes. Schools with wide premises and many entrance and exits surely need security guards. But with the limited number of security guards, not all gates are monitored. This study is for schools with limited security guards not proportion to the number of possible entrances and exits of the school. The system can only identify visible faces. Mask faces will be unidentified and can trigger the sound alarm. The study is ideal in the implementation and adoption of the system but the CCTV's resolution and connections must be improved and organized.

\section{References}

[1] S. Maeng. A Geometric Approach to Video Surveillance. Indian Journal of Science and Technology, 2015. Volume 8, Issue 21.

[2] H.J. Liao, C.H. R. Lin, Y.C. Lin, K.Y. Tung. Intrusion detection system: A comprehensive review. Journal of Network and Computer Applications, 2013. Volume 36, Issue 1, pp. 16-24.

[3] N. Tilley, A. Sidebottom. Handbook of Crime Prevention and Community Safety. Routledge, New York, 2017.

[4] D.S. Meganathan. System and Method of Monitoring the Video Surveillance Activities. US Patent 9,218,729, 2015.

[5] N. Boudriga, A WSN-Based System for Country Border Surveillance and Target Tracking. Scientific Research Publishing Inc., 2016. Vol. 5 No.1.

[6] Shivani and L. Kaur. A Brief Review: Border Intruder Detection System Based On Computer Vision. Imperial Journal of Interdisciplinary Research, 2016. Vol 2, No 7.

[7] D. Lyon, K. Ball, and K D. Haggerty. Routledge Handbook of Surveillance Studies. Routledge, New York, 2012, pp. 225-226.

[8] F. Flammini, R. Setola, and G. Franceschetti. Effective Surveillance for Homeland Security: Balancing Technology and Social Issues. CRC Press New York, 2013, P414.

[9] Lee, Kyu-Su; Sim, Hyeon; Oh, Jai-Cheol. The Design and Implementation of Intruder Access Control System by based of Ubiquitous Sensor Network. The Journal of the Korea institute of electronic communication sciences. 2012. Vol. 7, Issue 5, pp.1165-1171.

[10] John Brooke. SUS: A Retrospective. Journal of Usability Studies. 2013. Vol. 8, Issue 2, pp. 29-40.

[11] J. Jiang and G. Klein. Software Development Risks to Project Effectiveness. Journal of Systems and Software, 2000. Vol. 52, Issue 1, pp 3-10.

[12] L. G. Wallace and S. D. Sheetz. The adoption of software measures: A technology acceptance model (TAM) perspective. Information and Management, 2014. Vol. 51, Issue 2, pp. 249-259. 